\title{
FUZZY LOGIC CONTROLLER AS MODELING TOOL FOR THE BURNING PROCESS OF A CEMENT PRODUCTION PLANT
}

\author{
P. B. Osofisan and J. Esara \\ Department of Electrical and Electronics Engineering \\ University of Lagos, Nigeria \\ tosofisan@yahoo.com
}

\begin{abstract}
A comprehensive optimisation of the cement production process presents a problem since the input variables as well as the output variables are non-linear, interdependent and contain uncertainties. To arrive at a solution, a Fuzzy Logic controller has been designed to achieve a well-defined relationship between the main and vital variables through the instrumentality of a Fuzzy Model. The Fuzzy Logic controller has been simulated on a digital computer using MATLAB 5.0 Fuzzy Logic Tool Box, using data from a local cement production plant.
\end{abstract}

\section{OPSOMMING}

Die omvattende optimisering van ' $\mathrm{n}$ proses wat sement vervaardig, word beskryf deur nie-linieêre inset- en uitsetveranderlikes wat onderling afhanklik is, en ook van onsekere aard is. Om 'n optimum oplossing te verkry, word 'n Wasigheidsmodel gebruik. Die model word getoets deur gebruik te makk van die MATLAB 5.0 Fuzzy Logic Tool Box en data vanaf 'n lokale sementvervaardigingsaanleg. 


\section{INTRODUCTION}

Cement production can be roughly divided into quarrying, grinding, raw material mixing, burning, clinker milling and packaging. Comprehensive optimisation was considered impossible for some time, even though all the individual process stages had already been successfully automated. For the core-process, i.e. the burning of clinker in a rotary kiln, it had always been considered necessary to rely on the kiln operator's experience as a result of the complexity of the process.

The inputs and outputs of the rotary kiln are non-linear, interdependent and subject to long-term changes. The complexity of the process has its roots in the chemistry of the process and chemical reactions as well as the physical dimensions of the burning process.

Traditional control theory concentrates on eliminating the effects of disturbances to ensure stable operation of the process at a given set point. In clinker production, up to 20 process variables have to be considered every 3 to 12 minutes. Moreover, actual values and past history is required i.e. changes over the past one to four hours are important if kiln operation is to be stable [1].

To automate this process, a controller has to be designed that can mimic the operator by issuing the correct machine set-points for the control of the different parameters. Moreover, it must do this at least as well if not better than the best human operation.

Figure 1 shows the structure of an ordinary control system and an expert system with integrated control.
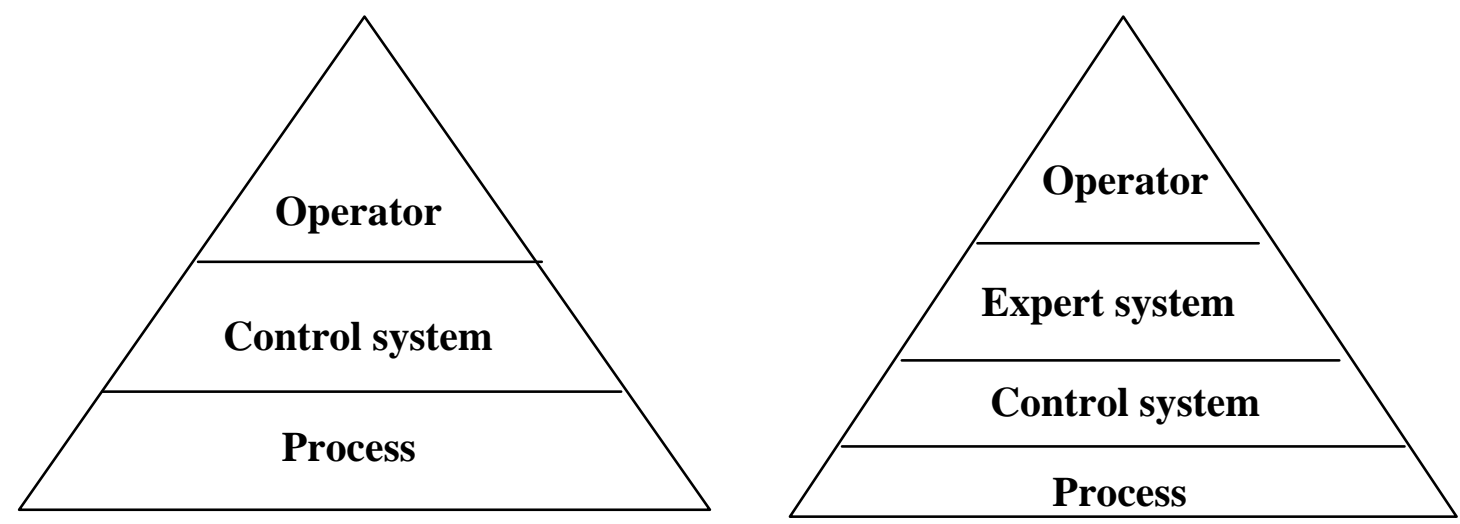

Figure 1: Structure of an ordinary control system and a control system with an integrated expert system

\section{FUZZY LOGIC}

In cement production, as in many other processes, traditional false/true logic cannot adequately deal with the situation in which there are a number of ambiguities or exceptions.

Fuzzy logic developed by L. Zadeh in the 1960s, provides the solution. It allows the 
mathematics of imprecision to be handled by dealing with phrases like "low', "high', "ok", or "may be". This is because it interpolates between a set of fuzzy rules. The fuzziness is introduced by allowing overlaps of the so-called membership functions [2].

During the past several years, Fuzzy Logic Control (FLC) has been successfully applied to a wide variety of practical problems.

Fuzzy control has been effectively used in the context of complex ill-defined processes, especially those which can be controlled by a skilled human operator without the knowledge of the underlying dynamics. In this sense, neural and adaptive fuzzy systems have been compared to classical control methods by Kosko [3].

\section{FUZZY MODELLING}

In traditional system modelling for control design, the derivation of a mathematical model to describe the system requires an accurate understanding of all the variables involved. This is not always easy, if not impossible, for a complicated system. In contrast, fuzzy modelling deals with the relationship of the output to the input, lumping many parameters together. Three fundamental aspects in establishing a fuzzy model for a system need to be addressed: [4]

i. Derivation of a linguistic description

ii. Implementation of the fuzzy model; which may be costly; and

iii. Effective use of mixed fuzzy -numerical data.

\subsection{Design procedure for a fuzzy logic controller[5]}

In the design of a fuzzy logic controller, the focus is the human operator's behavour. In the fuzzy logic controller, adjustments are handled by a fuzzy rule-based expert system, a logical model of the thought processes of a person in the course of manipulating the system.

Many applications show that FLC is superior to conventional control algorithms in terms of design simplicity and control performance. In particular, the FLC methodology appears very appealing when the processes are too complex for analysis by conventional quantitative techniques or when the available sources of information are interpreted quantitatively inexactly, or uncertainly. Thus, FLC may be viewed as an approach combining conventional precise mathematical control and humanlike decision-making.

A basic FLC system is shown in Figure 2, which has four principal components:

i. A Fuzzification interface (FI), which is somewhat like an $\mathrm{A} / \mathrm{D}$ converter in digital control

ii. A decision-making logic (DML), which is like digital control

iii. A defuzzification interface (DFI), which functions like digital control 


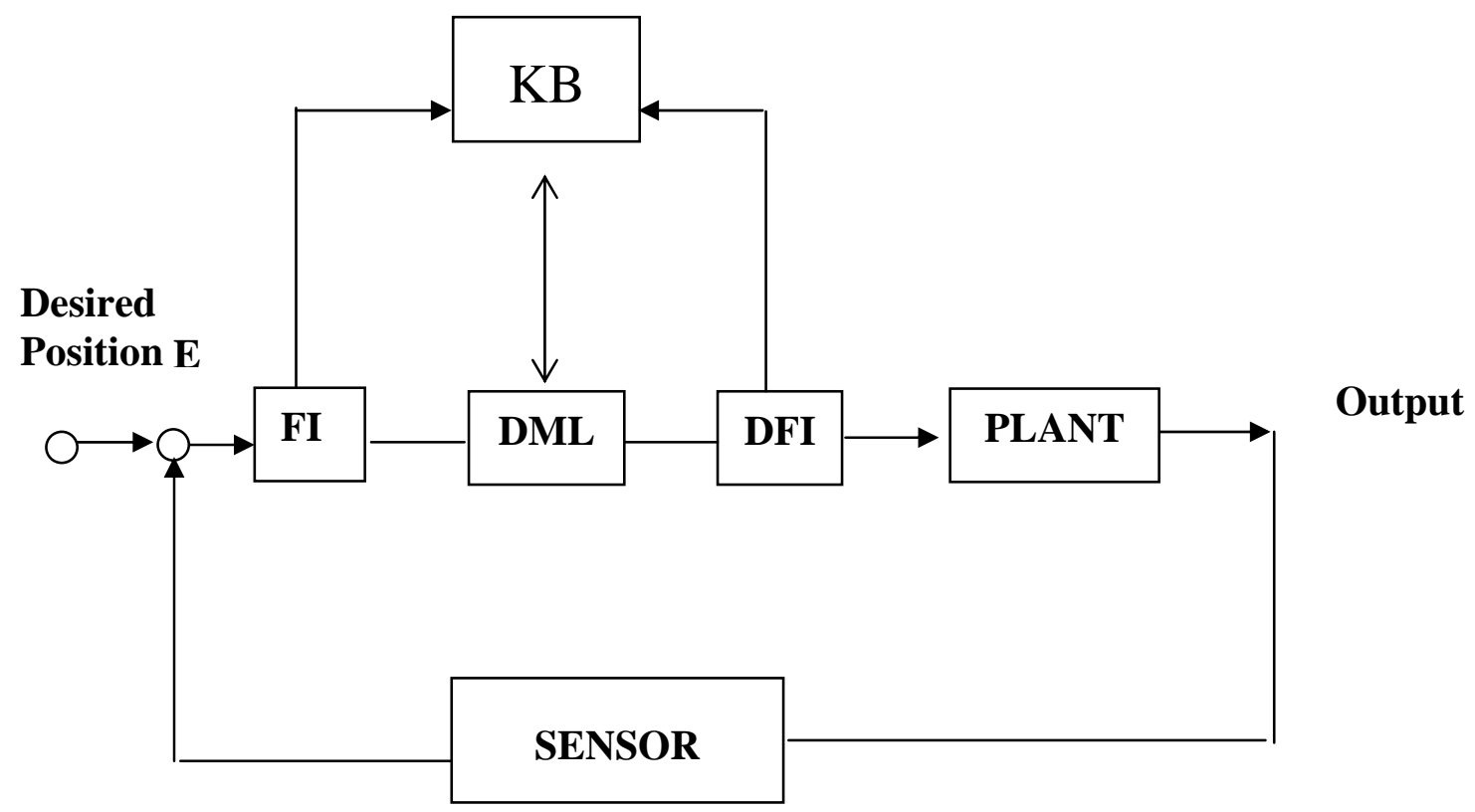

KB: Knowledge Base, FI: Fuzzification Interface, DML: Decision Making Logic, DFI: Defuzzification Interface

Figure 2: Basic Configuration of a Fuzzy Logic Control System

\subsection{Fuzzification interface}

The fuzzification is a subjective valuation procedure that transforms a measurement into a subjective value. It can be defined as a mapping from an observed input space to fuzzy sets in certain input universes of discourse.

\subsection{Decision-making}

Fuzzy control rules have the form of fuzzy conditional statements that relate the input fuzzy sets in the antecedent to process controlled inputs in the consequence.

\subsection{Deffuzzication interface}

Defuzzification Strategy is a mapping from a space of fuzzy control actions defined over a universe of discourse into a space of non-fuzzy (crisp) control actions. At present commonly used strategies [4] may be described as the max criterion, the mean of maximum, and the centre of area methods.

\subsection{Knowledge Base}

The knowledge base (KB) of an FLC consists of two components: A database and a fuzzy rule base. 


\subsubsection{Data Base}

An FLC data base contains knowledge used to characterize fuzzy control rules and fuzzy data manipulation in an FLC, which are based on experience and engineering judgment. In this sense, an appropriate choice of the membership functions of a fuzzy set plays a crucial role in the success of an application. The following aspects should be addressed.

i. Discretization and normalization of the universe of discourse

ii. The fuzzy partition of input and output spaces

iii. Completeness

iv. Membership function of a primary fuzzy set.

\subsubsection{Rule Base}

The fuzzy rule base is characterized by construction of a set of linguistic rules based on experts knowledge. The expert knowledge is usually in the form of IF-THEN rules, which can be easily implemented by fuzzy conditional statements. The following aspects are related to the construction of the rule base:

i. $\quad$ Choice of process state variables and control variables of fuzzy control rules

ii. Source and derivation of fuzzy control rules. There are four modes of derivation for fuzzy control rules: (a) derivation based on expert experience and control engineering knowledge; (b) emulation of operator's control actions, (c) fuzzy modeling of a process, and (d) learning

iii. Justification of fuzzy control rules

iv. Types of fuzzy control rules: Two types of fuzzy control rules: state evaluation fuzzy control rules, and object evaluation fuzzy control rules are widely used in the design of FLC

v. Number of fuzzy rules

vi. Consistence of fuzzy control rules

vii. Completeness of rule base

\section{CASE STUDY AND RESULT}

Kiln 3 of West African Portland Cement Plant located in Western Nigeria was selected for the case study. The experience of an operator who has worked at the plant for 15 years is used to obtain the rule base. This operator is considered as an expert in the problem of defining the fuzzy set and fuzzy rules. 


\section{RULE BASE}

Feed Rate

\begin{tabular}{|c|c|c|c|c|c|}
\hline \multirow{2}{*}{$\begin{array}{l}\text { Back-end } \\
\text { Temperature }\end{array}$} & \multicolumn{2}{|c|}{$\begin{array}{l}\text { Burning zone } \\
\text { Temperature }\end{array}$} & & & \\
\hline & Very Low & Low & Normal & High & Very High \\
\hline Very Low & 1 & 1 & 1 & 1 & 1 \\
\hline Low & 1 & 2 & 2 & 1 & 2 \\
\hline Normal & 1 & 2 & 3 & 2 & 5 \\
\hline High & 2 & 2 & 4 & 4 & 5 \\
\hline Very High & 1 & 2 & 5 & 5 & 5 \\
\hline & $\begin{array}{l}1=V \\
2=L\end{array}$ & Low & $\begin{array}{l}=\text { Norr } \\
=\text { High }\end{array}$ & 5 & Very High \\
\hline
\end{tabular}

Figure 3.1: Fuzzy rules for feed rate

\section{Fuel Rate}

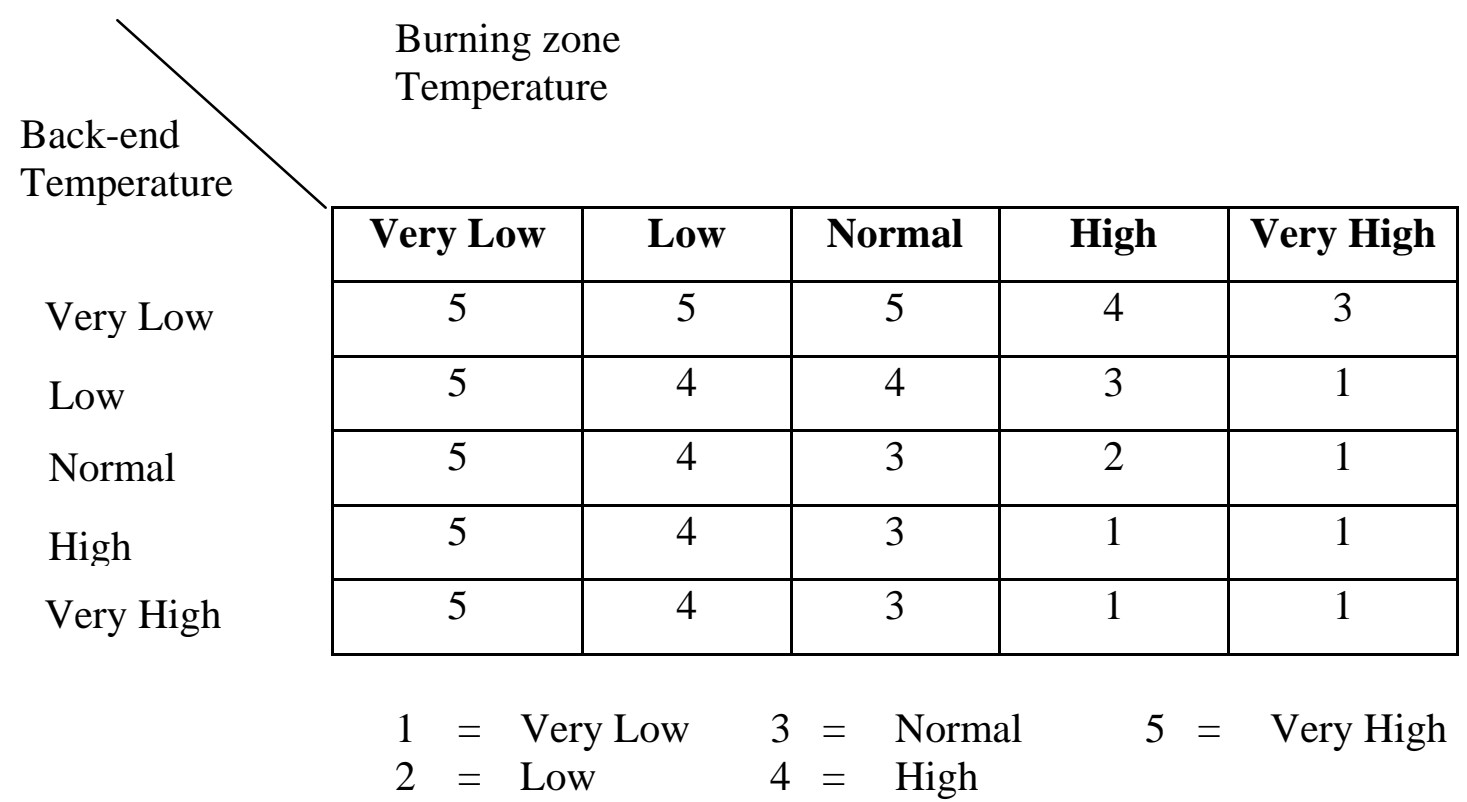

Figure 3.2: Fuzzy rules for fuel rate 


\section{Kiln Speed}

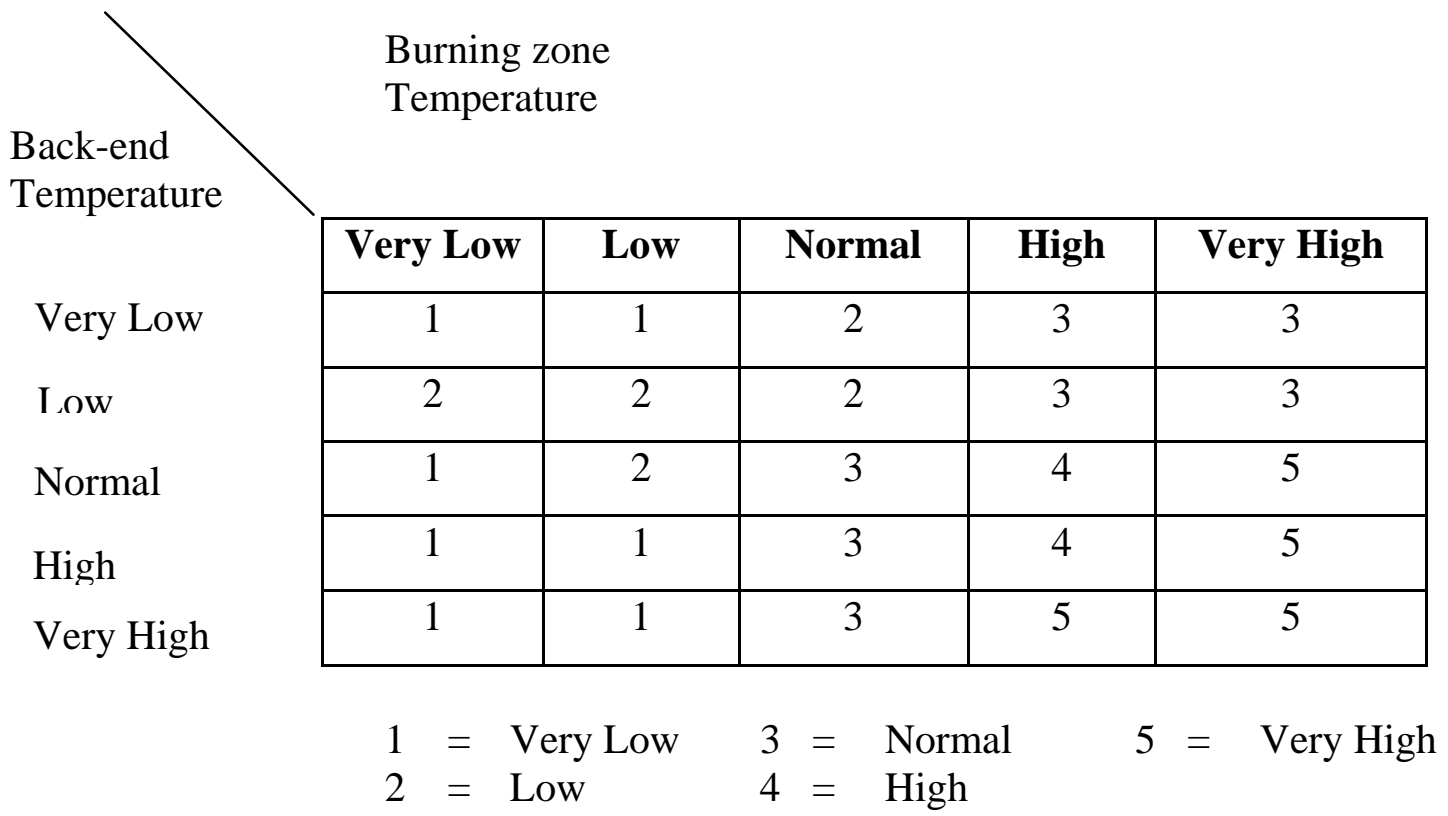

Figure 3.3: Fuzzy rules for kiln speed

\subsection{Formation of fuzzy sets}

The membership function plots for the fuelrate, feedrate, kiln speed, and backend temperature i.e. preheater temperature and the burning zone temperature which are the critical parameters in the clinker burning process are given in Figures 4.1 to 4.5. From these data the rule base for the Fuzzy Logic Controller is designed.

\section{Membership Function Plots}

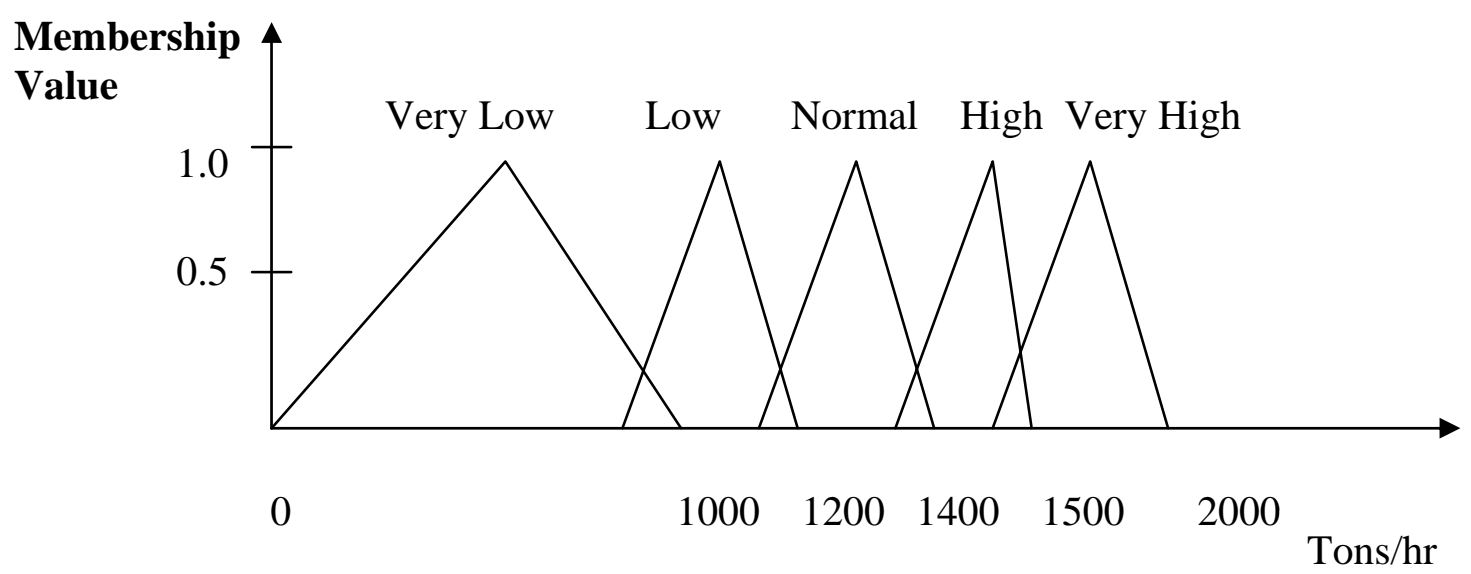

Figure 4.1: Membership function for the feed rate 


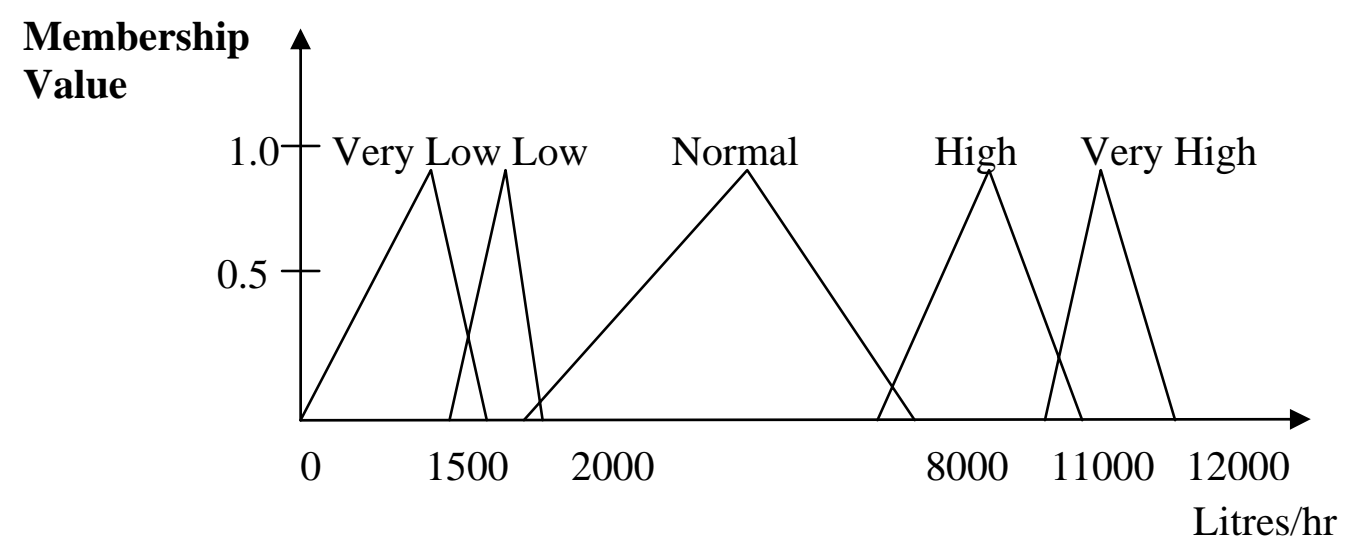

Fuelrate

Figure 4.2: Membership function for the fuel rate

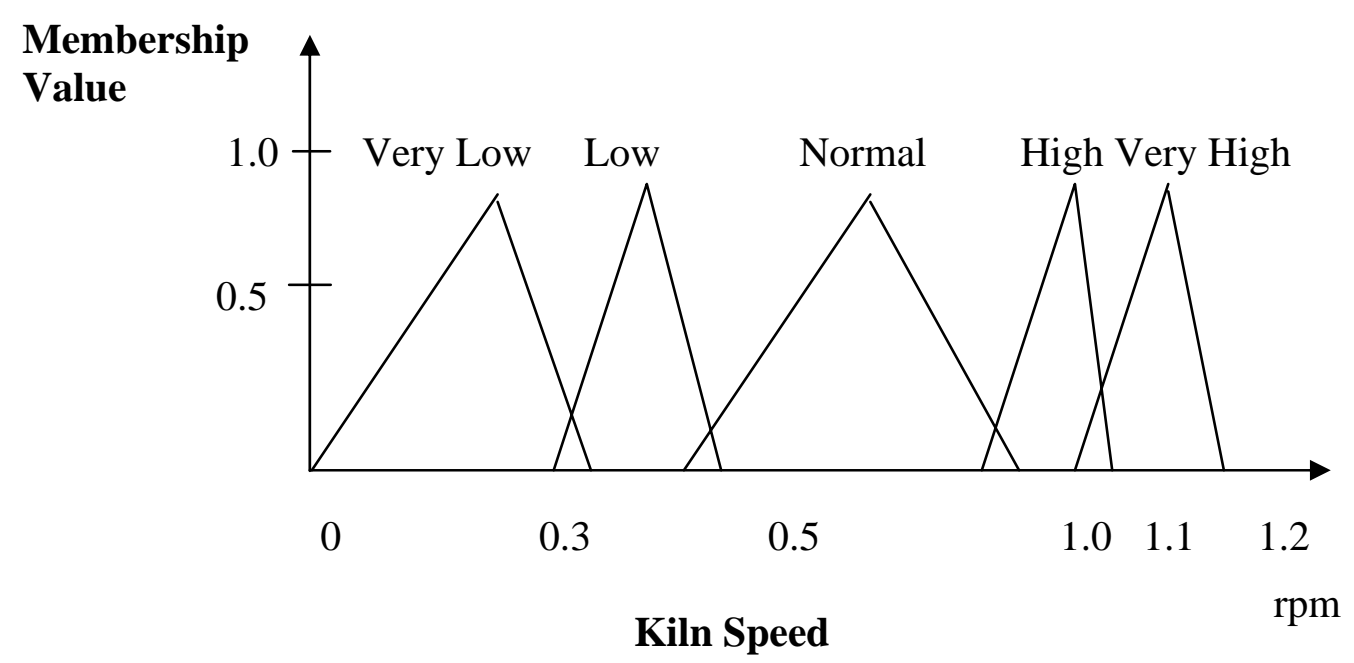

Figure 4.3: Membership function for the kiln speed

Membership

Value

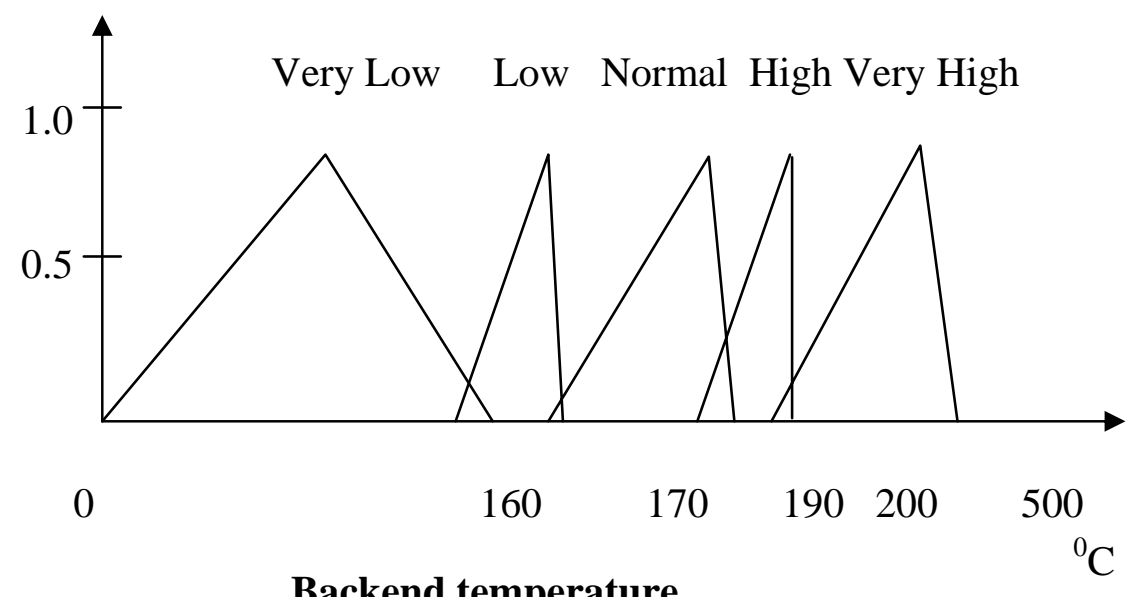

Backend temperature

Figure 4.4: Membership function for the backend temperature 


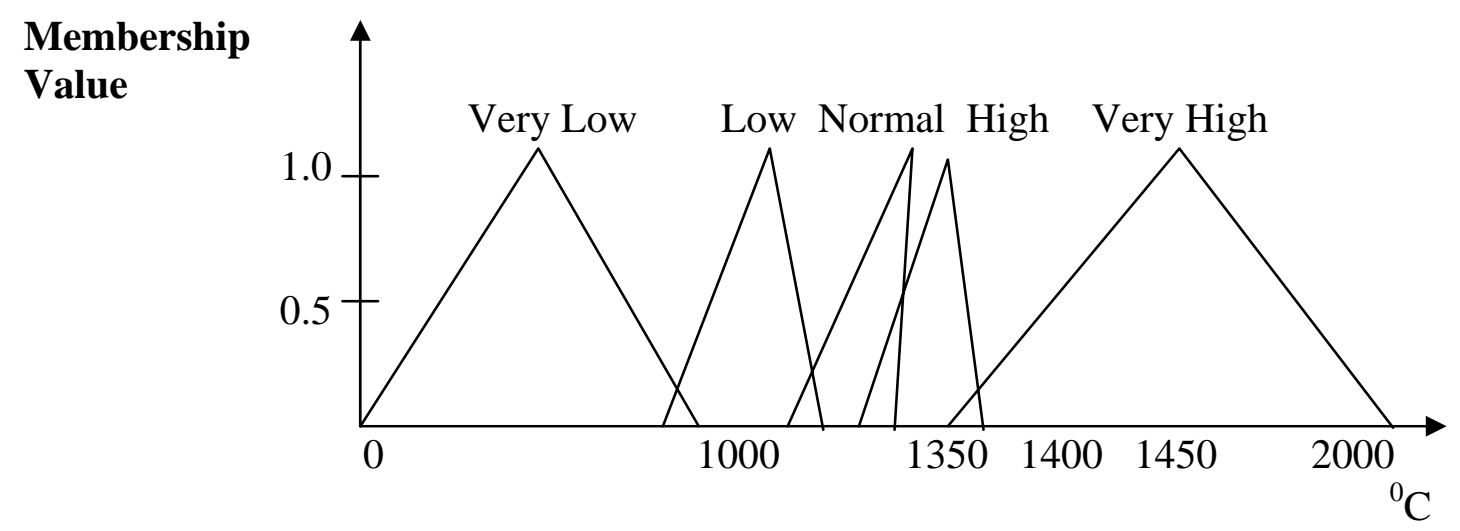

Burning zone temperature

Figure 4.5: Membership formation for the burning zone temperature

The fuzzy supervision controller was simulated using MATLAB. 5.0 Fuzzy Logic Toolbox. The intention is to establish a functional relationship between the input variables, i.e. backend temperature and burning zone temperature and the output variables i.e. the feedrate, the fuel rate and the kiln speed. These variables are the critical ones in respect of energy consumption, refractory consumption, clinker quality and production output.

It is necessary to have a fuzzy model whereby the relationship between the two main input variables and the three main output variables can be established.

\subsection{Reactions in the rotary kiln}

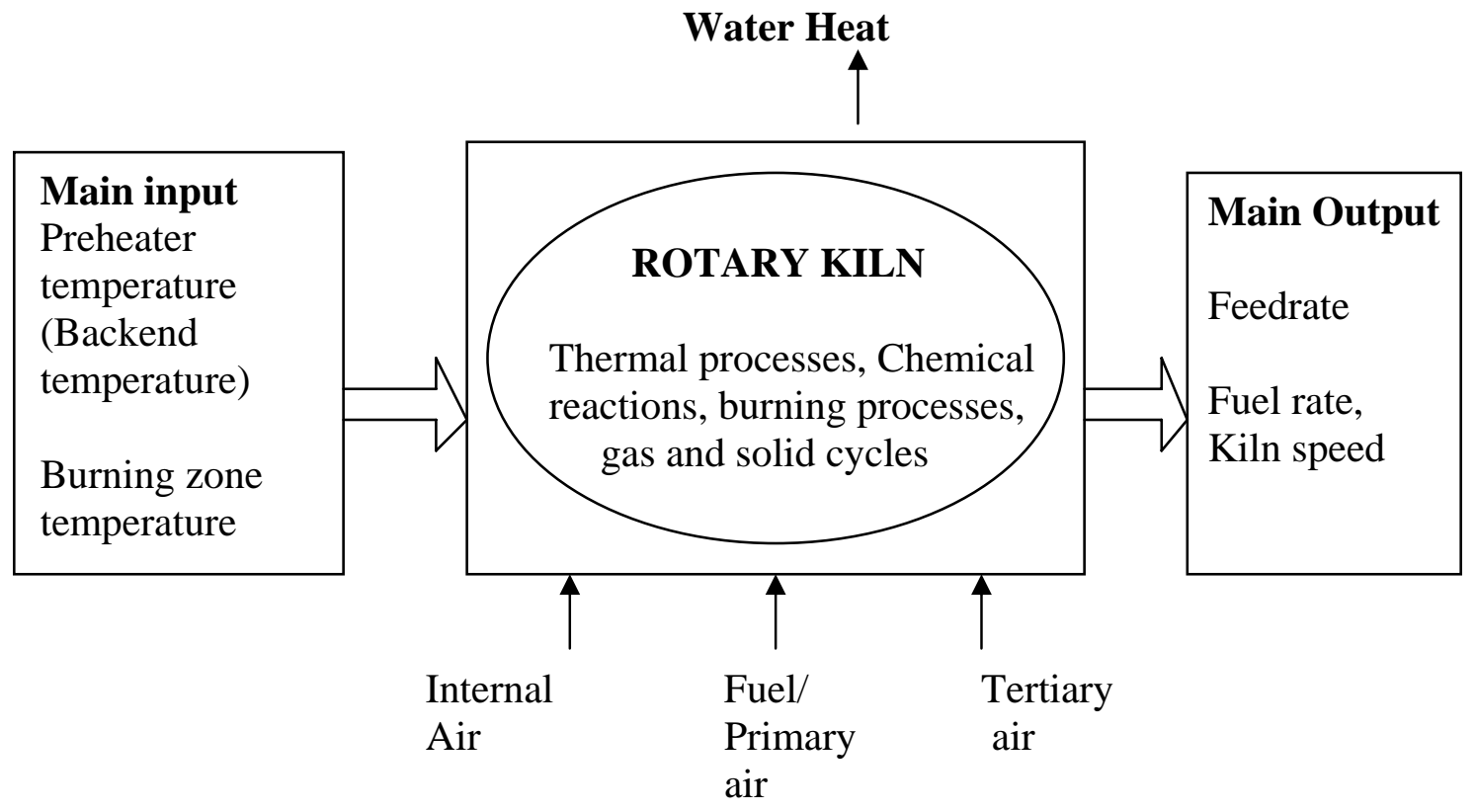

Figure 5: Reactions in a rotary kiln 
The following objectives were set to scrutinize the burning process in the rotary kiln:

i. Reduction of energy waste

ii. Increase in production output

iii. Increase in the lifespan of the refractory in the kiln

iv. Reduction of pollutant emissions e.g. $\mathrm{O}_{2}, \mathrm{NO}_{2}$

It has been found that these objective goals are dependent on certain parameters viz.

i. Production output is a function of the feedrate of the raw material

ii. Energy consumption is a function of the feedrate

iii. The lifespan of the refractory is a function of the induction fan speed which supplies the combustion air

iv. The emission from the kiln is a function of the kiln speed which regulates the amount of $\mathrm{O}_{2}$ surplus on the kiln

Therefore the following 4 parameters are monitored for optimisation purposes

i. $\quad$ Burning zone temperature

ii. Backend temperature (preheater temperature)

iii. Kiln hood temperature

iv. $\quad \mathrm{O} 2$ surplus in the kiln

The following four parameters are also chosen as fuzzy variables and are selected as the "most important state variables". They are
i. $\quad$ Feedrate
ii. Fuelrate
iii. Kiln speed
iv. Induction fan speed

\subsection{Results obtained}

Figures 6 to 11, show the results in graphical form. They are typical curves of

i. Fuelrate as a function of the burning zone temperature and backend temperature (Figures 6 and 7),

ii. Kiln speed as a function of the burning zone temperature and backend temperature (Figures 8 and 9), and

iii. Feedrate as a function of the burning zone temperature and backend temperature (Figures 10 and 11).

\subsection{Comments on the results obtained}

Figure 6 shows that the fuel rate reaches a peak when the burning zone temperature reaches $\left(2 \times 10^{3}\right)^{\circ} \mathrm{C}$. At the time when the burning zone temperature reaches $(3 \mathrm{x}$ 


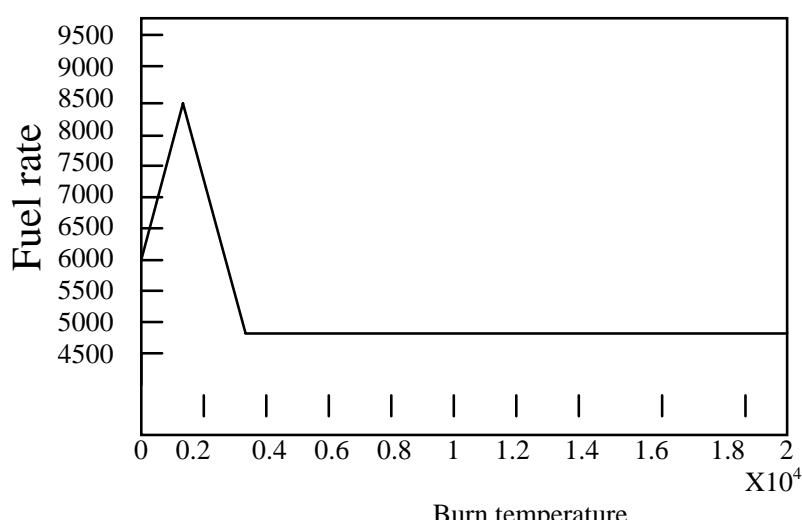

Figure 6: Fuel rate as a function of burning zone temperature

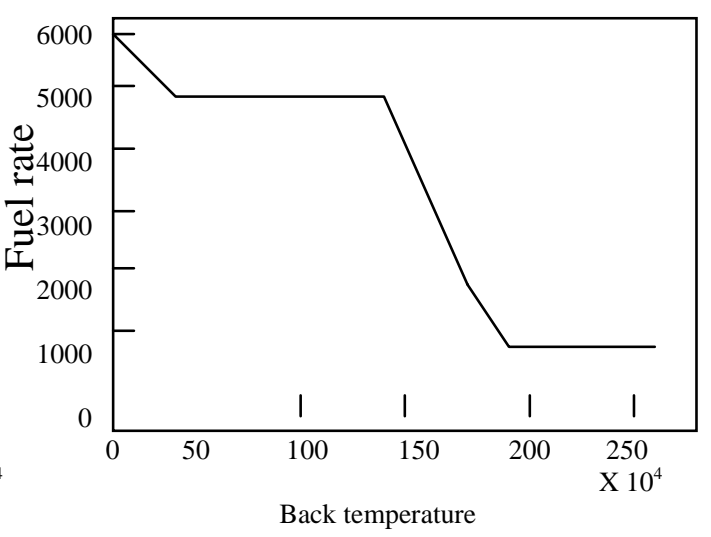

Figure 7: Fuel rate as a function of backend temperature

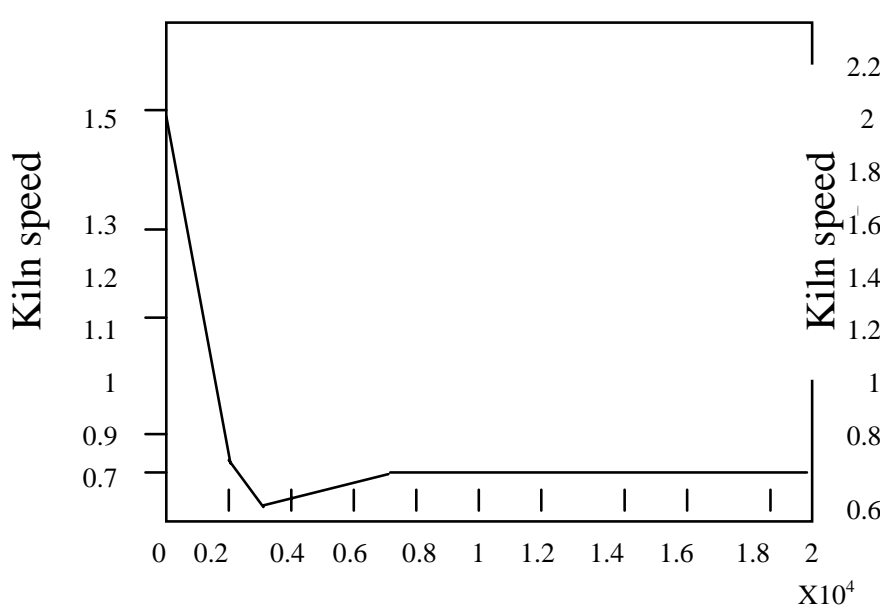

Burn temperature

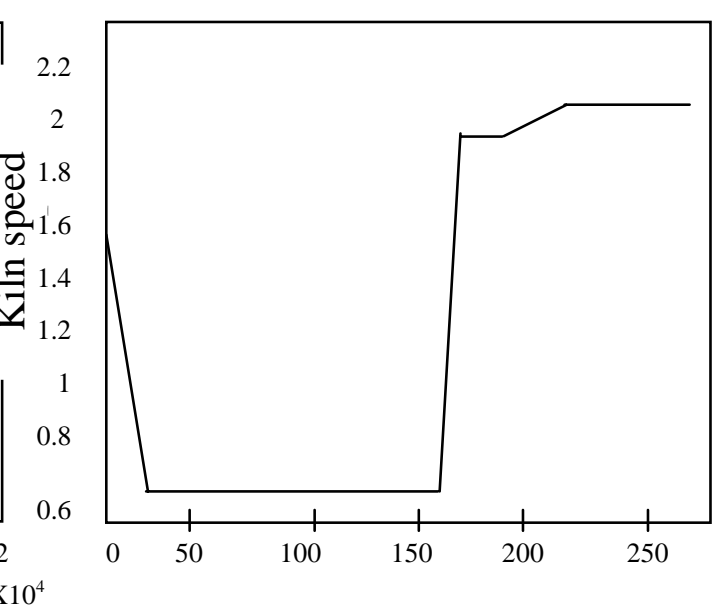

Back temperature

Figure 8: Kiln speed as a function of burning Figure 9: Fuel rate as a function zone temperature backend temperature

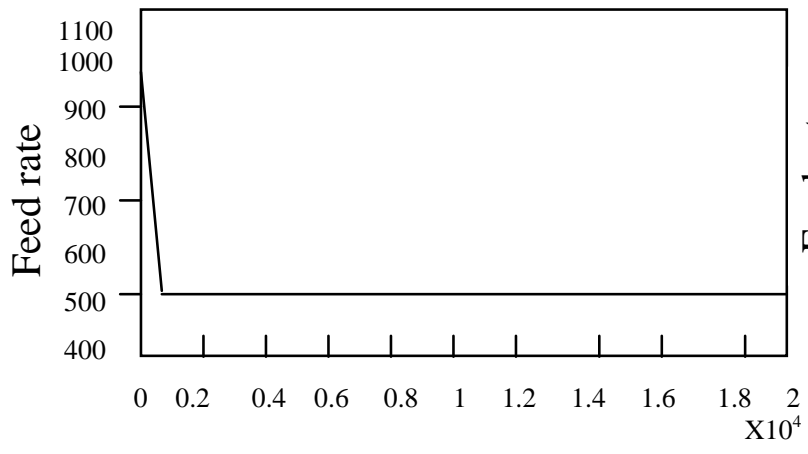

Burn temperature

Figure 10: Feed rate as a function of burning zone temperature

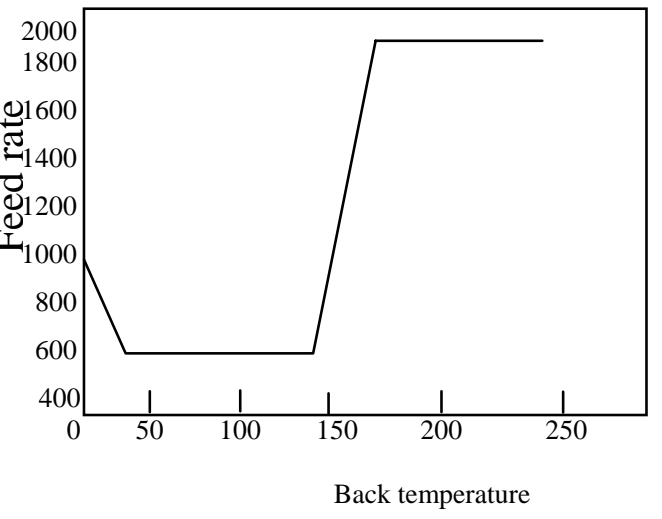

Figure 11: Feed rate as a function of backend temperature 
$\left.10^{3}\right){ }^{0} \mathrm{C}$, the fuel rate stabilizes at a constant value and remains at this level until the maximum temperature of $\left(20 \times 10^{3}\right){ }^{\circ} \mathrm{C}$ is reached. That means that an increase in the input variable i.e. the burning zone temperature does not bring any significant change in the fuel rate. The energy consumption therefore remains constant as soon as the burning zone temperature reaches $2000^{\circ} \mathrm{C}$. To save fuel, the burning zone temperature can be kept constant at $2000^{\circ} \mathrm{C}$.

Figure 7 shows that the fuel rate remains constant when the backend temperature i.e. the preheater temperature is between $20^{\circ} \mathrm{C}$ and $130^{\circ} \mathrm{C}$, then at $130^{\circ} \mathrm{C}$ the fuel rate decreases sharply to approximately 1000 litre/hr and remains constant until the preheater reaches the maximum value. It means that the energy consumption is high at the initial stage when the preheater temperature is increasing, and when the temperature reaches $160^{\circ} \mathrm{C}$, the fuel consumption reduces to a minimum of 1000 liter/hour.

Figure 8 shows that the kiln speed is high $(1.5 \mathrm{rpm})$ at the initial stage but decreases linearly up to the point when the burning zone temperature reaches $2600^{\circ} \mathrm{C}$. When the burning zone temperature reaches $6800^{\circ} \mathrm{C}$, the kiln-speed remains constant at 0.73rmp. The emission of $\mathrm{O}_{2}, \mathrm{NO}_{2}$ and other gases is high at the onset of the operation but as soon as the burning zone temperature reaches $1900^{\circ} \mathrm{C}$, the emission becomes minimal.

Figure 9 shows that the kiln speed is high (1.5rpm) at the initial stage but drops linearly to $0.7 \mathrm{rpm}$ at the point where the preheater temperature reaches $20^{\circ} \mathrm{C}$. The kiln speed remains until the temperature reaches $150^{\circ} \mathrm{C}$ and from that point the kiln speed rises to $2.15 \mathrm{rpm}$ and rises higher as the preheater temperature reaches the maximum. Therefore the safest region where the kiln operates with the least emission of pollutants is when the preheater temperature (backend temperature) lies between $20^{\circ} \mathrm{C}$ and $150^{\circ} \mathrm{C}$.

Figure 10 shows that the feedrate at the initial point is high (1000 ton/hr) but decreases linearly to $500 \mathrm{ton} / \mathrm{hr}$ at the point where the burning zone temperature reaches $1500^{\circ} \mathrm{C}$. It remains constant until the maximum burning zone temperature is reached. That means that, as soon as the burning zone temperature of $2000^{\circ} \mathrm{C}$ is reached, the production output remains constant, no matter how one increases the temperature of the burning zone.

Figure 11 shows that the feedrate is high $(1,000$ tons/hr) at the onset but decreases linearly to 500 tons $/ \mathrm{hrs}$ at the point where the preheater temperature reaches $20^{\circ} \mathrm{C}$. It remains at this value until the preheater temperature reaches $145^{\circ} \mathrm{C}$. From this point the feed rate increases linearly to 1800 ton/hr and remains at this value up to the point where the temperature of the preheater reaches its maximum. That means, that the production output is slightly high at the initial stage but drops to half its value when the preheater temperature reaches $20^{\circ} \mathrm{C}$, but later at $145^{\circ} \mathrm{C}$ the production output rises to 1800 tons/hr with a further increase in temperature. 


\section{CONCLUSION}

It has hitherto been difficult to get a good functional mathematical model for the burning process, but in this work the application of a Fuzzy Logic Controller has proved to be capable of providing a workable fuzzy model which implies that the optimisation of the whole production process can now be carried out. Generally, an optimisation problem would require that a given objective (or fitness) function is minimized or maximized.

The computation of optimal values of the tunable parameters e.g. scaling factor, membership functions, rules, etc. needs the required control objectives as well as the fixed model of the controller (FLC). Genetic Algorithms can be used to locate efficient FLC rules since they search large spaces efficiently without the need for derivative information. Using a Genetic Algorithm it is possible to design a fitness function that is capable of optimizing the performance of the process so that the optimisation of the whole production process of the cement plant can be carried out systematically without much difficulty. The Fuzzy Model which was designed, is capable of taking care of the uncertainties and imprecision which are normally characteristic of the burning process.

\section{REFERENCES}

[1] Krings L. and Hasped D. W, 1995. "Linkman in Cement Production: Optimisation beyond traditional control”. ABB Review June/July 1995. pp.32 $-38$.

[2] Isaka S., Chu V. K., 1991. "Industrial Fuzzy Control Review: A perspective from Feedback and Manufacturing". Advances in Fuzzy Systems. Applications and Theory Vol. 2 World Scientific Publishing Co. Pte. Ltd. Singapore.

[3] Kosko B., 1991. "Neural Networks and Fuzzy Systems: A dynamical Systems Approach to Machine Intelligence”. Prentice - Hall Englewood Cliffs, N. J., 1991.

[4] Lee C. C, 1995. "Fuzzy Logic in Control System: Fuzzy Logic Controller Part I and Part II”. IEEE Trans Systems Man and Cybernetics 20, 1990. pp. 404418.

[5] Chin-Fan-Lin, 1994. "Fuzzy Logic Controller Design” Advanced Control Systems Design. Prentice Hall, 1994. pp. 431460.

[6] Self K., 1990. “Designing with Fuzzy Logic”. IEEE Spectrum, pp. 42-44. 